\title{
Recrystallization and Melting of Partially Melted Stark Rubber
}

\author{
Donald E. Roberts
}

\author{
Institute for Materials Research, National Bureau of Standards, Washington, D.C. 20234
}

(January 27, 1967)

\begin{abstract}
Two specimens from a piece of stark rubber which had a melting temperature originally at $41{ }^{\circ} \mathrm{C}$ were partially melted at $38{ }^{\circ} \mathrm{C}$ and allowed to stand for 11 years, one at about $25^{\circ} \mathrm{C}$, the other at $38{ }^{\circ} \mathrm{C}$. The first showed a continuous slow decrease in specific volume, while the second increased slowly in volume for 5 months and remained constant for about 5 months more before showing the continuous slow decrease. The melting temperature of the first increased to $45{ }^{\circ} \mathrm{C}$ and the melting range was broadened. The melting temperature of the second became $52{ }^{\circ} \mathrm{C}$ and the range was narrowed. Perfecting or enlarging of crystals and the effect of higher recrystallization temperatures have influenced the melting temperatures. The effect of heating rate is discussed in connection with slow increases in volume, attributed to relaxation of oriented regions, during melting.
\end{abstract}

Key Words: Crystal size, crystallized rubber, heating rate, melting range, melting temperature, oriented, partial melting, recrystallization, rubber, slow melting, stark rubber.

\section{Introduction}

The term "stark" was originally applied to hard crystalline regions which formed in bales of rubber during storage. The term can be used in referring to rubber which has been deformed in some way, then crystallized so that an oriented system of crystallites results which is stable above room temperature. ${ }^{1}$ Its crystallization and melting are similar to those of undeformed rubber crystallized by cooling, except that the temperatures of these processes are shifted upward several degrees for stark rubber.

This paper presents the results of two experiments which are a continuation of work described in a previous paper on the nature of stark rubber [1]. ${ }^{2}$ The specimens used in the present work are from the same source as Sample II, illustrated in figure 1 of that paper, namely smoked sheet, highly milled, then kept in a basement for 15 years. After the sample was discovered to have become stark, it was returned to the laboratory and the several specimens were removed from it. The temperature during the storage period is not known, although it is unlikely that it differed appreciably from the range 15 to $25{ }^{\circ} \mathrm{C}$. Orientation in stark rubber $[2,3]$ facilitates the crystallization near room temperature, where the rate of crystallization for undeformed rubber is negligible [4]. X-ray diffraction [1] indicated that the stark rubber crystallites were oriented as a result of the milling process.

\footnotetext{
' Not to be confused with racked rubber, which has been severely and repeatedly stretched at elevated temperatures and cooled to yield a fiber.

${ }^{2}$ Figures in brackets indicate the literature references at the end of this paper
}

The $d$-spacings indicated that the crystalline form in stark rubber is the same as that in stretched or cooled rubber [1]. Molecular weights were not determined; a recent paper [5] discusses the effects of milling on the molecular weight of rubber. The observed melting temperature $\left(T_{m}\right)$, without annealing, of Sample II in 1952 was $41{ }^{\circ} \mathrm{C}$.

Stark rubber requires a very long time to approach phase equilibrium at any temperature below its $T_{m}$, therefore an experiment was started in which sufficient time could be allowed at a fixed temperature near $T_{m}$ for the process to run through whatever changes might occur. At the same time another experiment was started to see if recrystallization of the partially melted stark rubber could be observed at room temperature. These experiments were begun in 1953 and finished in 1965.

\section{Experimental Procedures}

Two dilatometers were assembled, each containing about $2.7 \mathrm{~g}$ of the stark rubber. Their thermal histories are represented in figures 1 and 2 . The dilatometers were heated from 30 to $38{ }^{\circ} \mathrm{C}$ in 7 days, remaining at $38{ }^{\circ} \mathrm{C}$ for one day, then one (Sample A) was returned to room temperature (avg $25^{\circ} \mathrm{C}$, limits 21.5 and $29.5^{\circ} \mathrm{C}$ ) and the other (Sample B) was kept at $38{ }^{\circ} \mathrm{C}$ (limits 37.7 and $38.3^{\circ} \mathrm{C}$ ). Sample B was unintentionally overheated for a period of a few hours during which the temperature briefly reached $39.8{ }^{\circ} \mathrm{C}$. This occurred 2 weeks after the experiment began and resulted in a small irreversible increase in volume. 
In Sample $\mathrm{A}$ at room temperature an induction period of about 20 days was followed by a decrease in volume and the recrystallization ${ }^{3}$ eventually progressed until a greater degree of crystallinity existed than that at room temperature before heating. In Sample B there was a continued increase in volume ${ }^{4}$ until a maximum was reached after 5 months. This volume was constant for an additional 4 to 5 months, then a decrease began. Neither of these recrystallization rates had yet begun to diminish on a log time plot by the time the final heating was begun in 1964 . Presumably the recrystallization might have gone on for many years longer. For the recrystallization, occurring in the presence of existing crystals, the Avrami exponent $n$ is a little less than 1 for each of the two samples. Isotherms with $n$ near 1 have been noted in seeded crystallization $[6,7,8]$. The crystallinities of the specimens, calculated from the specific volumes

${ }^{3}$ To simplify terminology the term "recrystallization" in this paper may be understood to include any of the processes which occur when a sample is stored or annealed: Crystal. lization, enlarging or thickening of crystals, and removal of voids and defects.

${ }^{4}$ Following the overheating, when the temperature had returned to $38{ }^{\circ} \mathrm{C}$, the volume remained constant for 10 days then continued its upward crawl.

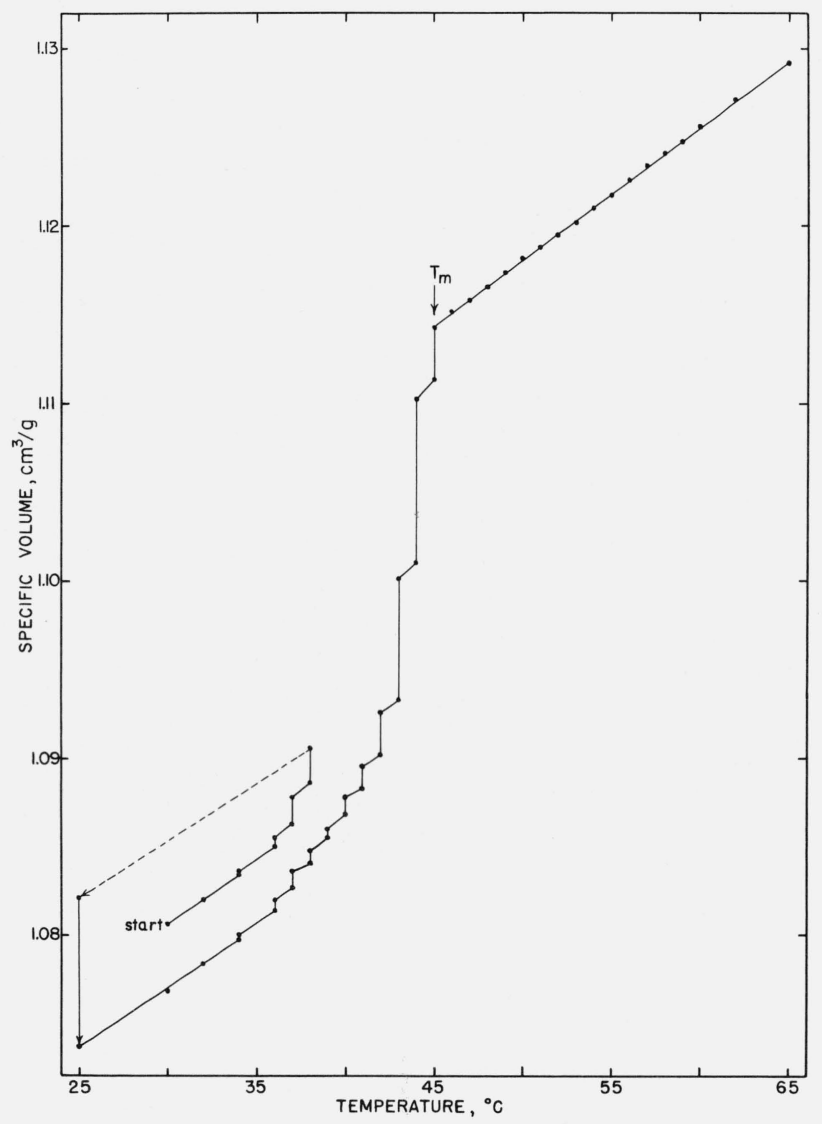

FigURE 1. Thermal history of stark rubber Sample A from 1953 to 1965 .

The vertical lines show the volume increases during the observation period at those temperatures. $T_{m}$ is taken as that temperature at which volume increase with time ceases. Irregularities in the slopes of the "thermal expansion" lines result from differences in times of initial readings after heating. at $30{ }^{\circ} \mathrm{C}$ as shown in figures 1 and 2 , were approximately as follows:

Amorphous rubber

Initial stark rubber

$1.1032 \mathrm{~cm}^{3} / \mathrm{g}$

$0 \%$

Recrystallized Sample A

1.0807

$23 \%$

Recrystallized Sample B

1.0770

$26.5 \%$

Ideal crystal calculated from unit cell

1.0875

$16 \%$

1.005

$100 \%$

After 11 years at the stated temperatures, Sample B was cooled to $30^{\circ} \mathrm{C}$, then the dilatometers were heated so as to reach $36^{\circ} \mathrm{C}$ in 3 days and $38^{\circ} \mathrm{C}$ in 7 days more. The subsequent heating rate was usually stepwise $1 \mathrm{deg}$ C per week (6-8 days), which approximates the heating schedule used for Sample II in the previous work [1], and permits proper comparison of their melting temperatures. See figures 1 and 2.

\section{Results and Discussion}

During the period each sample was held at $38{ }^{\circ} \mathrm{C}$, some of the less stable crystals were melted, thus raising the average and narrowing the distribution of crystal sizes.

Upon first heating of the specimens, before the recrystallization, as well as in the melting of Sample II,

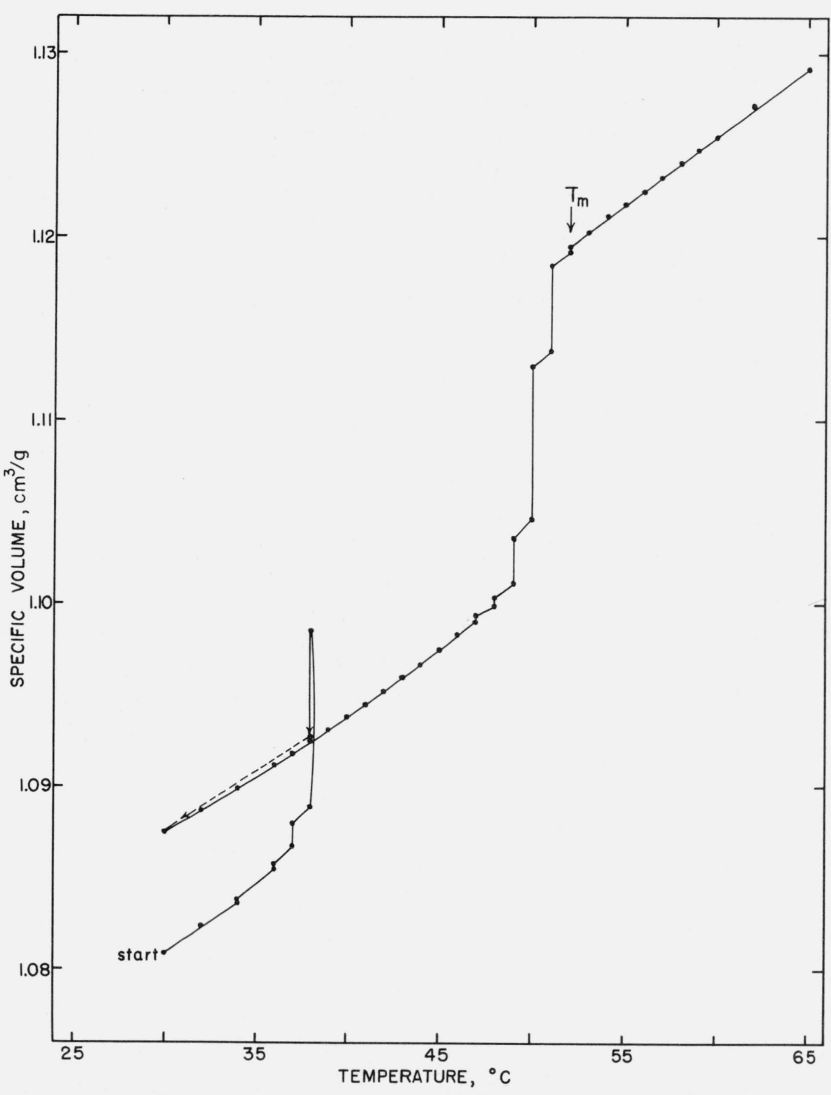

Figure 2. Thermal history of Sample B. 
the melting process begins to produce an increase in volume (beyond normal thermal expansion) at about $34{ }^{\circ} \mathrm{C}$. Also for Sample A, this is observed upon the final heating after recrystallization, and the melting range is broadened so that $T_{m}$ is now $45^{\circ} \mathrm{C}$ compared to $41{ }^{\circ} \mathrm{C}$ for the earlier specimen. Apparently a broader distribution (raising the upper limit) of crystallite size and perfection was developed by the long-time recrystallization at room temperature.

Upon final heating of Sample B, on the other hand, the additional increase of volume begins to appear at $47^{\circ} \mathrm{C}$, only $5 \mathrm{deg}$ below $T_{m}$. In each case the increase of volume began at $9 \mathrm{deg}$ above the recrystallization temperature. In previous work [4] at lower temperatures this difference ranged from 7 to a minimum of $4 \mathrm{deg}$, increasing to $9 \mathrm{deg}$ as the crystallization temperature was raised to $15{ }^{\circ} \mathrm{C}$. The annealing at $38{ }^{\circ} \mathrm{C}$ apparently tended to eliminate defects, raising the low end of the melting range by $13 \mathrm{deg}$. At the same time it produced larger crystallites at the expense of smaller ones, raising the $T_{m}$ by $11 \mathrm{deg}$, to $52{ }^{\circ} \mathrm{C}$.

Increases of melting temperatures of rubber and other polymers after prolonged storage have been reported, and these have been attributed to growth of crystals or thickening of lamellae $[9,10,11,12]$. In the present work, perfecting or enlarging the crystals over a long time span and the effect of high temperatures of crystallization have operated similarly to raise the melting temperatures. At the same time the melting range for Sample B was narrowed from $7 \mathrm{deg}$ to $5 \mathrm{deg}$, in accordance with previous observations $[4,13]$ of a narrowing of the melting range at higher crystallization temperatures. The slow melting of crystals while the temperature was held at $38{ }^{\circ} \mathrm{C}$ is in accordance with previous observations [1], where it was found to occur in stark rubber at temperatures above $35{ }^{\circ} \mathrm{C}$. Figure 3 shows the volume-time relations observed for the final melting of Sample B, when it was held at each temperature for about a week.

The observed melting temperature in a sample of stark rubber having a given degree of orientation depends upon (1) the temperature of crystallization, (2) the age of the crystals, and (3) the heating rate. With regard to the heating rate, two influences are at work and the observed $T_{m}$ will depend to some extent upon which of the two dominates. On one hand there is the effect of the slowness of melting, and on the other hand there is the effect of annealing during the heating schedule. The temperature range where slow volume increases are observed ("melting range") is the critical region where heating rate is concerned. Outside this range, volume equilibrium is attained at the same time as thermal equilibrium.

The heating rate of $1 \mathrm{deg} /$ week used here does not allow time for the completion of phase changes below $T_{m}$. Consequently, the portions of the crystalline material that are unstable at a given temperature do not have time to melt completely, so that the volume increase at the next higher temperature is composed partly of the contribution from previously unstable crystals. This delay results in a higher observed $T_{m}$ than would occur if slower heating were to be used, e.g., holding the temperature until maximum volume had been reached at each temperature in the melting range (see figs. 1 and 2). However, if sufficient time

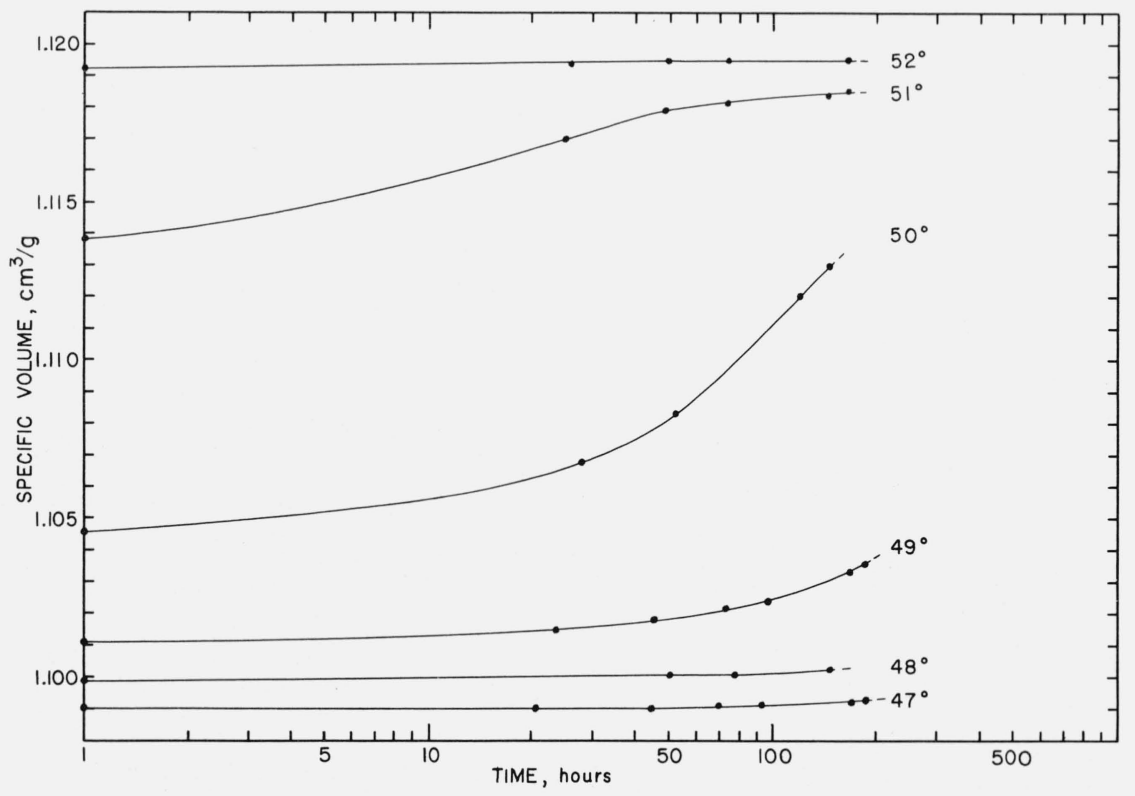

Figure 3. Melting kinetics of Sample $B$ in the range 47 to $52{ }^{\circ} \mathrm{C}$ $\left(=\mathrm{T}_{\mathrm{m}}\right)$.

A similar family of curves is obtained with Sample A between 34 and $45^{\circ} \mathrm{C}$. The average melting rates $\left(\mathrm{cm}^{3} / \mathrm{g} / \mathrm{hr}\right)$ between the points shown on, for example, the $50{ }^{\circ} \mathrm{C}$ curve are $0.0000822,0.0000634,0.0000551$, and 0.0000362 . 
(years) were to be allowed so that significant recrystallization could occur at each temperature, the crystallization temperature would be effectively raised and the $T_{m}$ would be correspondingly higher. Table 1 gives estimates of the effect of heating rate on $T_{m}$ in comparison with the present work. Another sample from the same source as Sample II melted $4 \mathrm{deg}$ higher than that sample when heated at $1 \mathrm{deg} / 4 \mathrm{~min}$.

It is not clear whether chain folded, extended chain or bundlelike crystals are present in stark rubber. Partially oriented systems might contain a mixture [14]. Considerable superheating in large, extended chain crystals has been reported [15].

TABLE 1

\begin{tabular}{|c|c|c|c|}
\hline \multirow{2}{*}{$\begin{array}{c}\text { Heating rate } \\
\text { one degree per }\end{array}$} & \multicolumn{2}{|c|}{ Influence of: } & \multirow{2}{*}{$\begin{array}{c}\text { Effect on } T_{m} \\
\text { compared with } \\
\text { present work }\end{array}$} \\
\hline & Delay & Annealing & \\
\hline $\begin{array}{l}\text { Hour............... } \\
\text { Week............ } \\
6 \text { Months }{ }^{\mathrm{a}} \ldots \ldots \ldots \\
10 \text { Years }{ }^{\mathrm{b}} \ldots \ldots \ldots\end{array}$ & $\begin{array}{l}\text { Strong.......... } \\
\text { Some............ } \\
\text { None.......... } \\
\text { None.......... }\end{array}$ & $\begin{array}{l}\text { None............ } \\
\text { None........... } \\
\text { Slight.......... } \\
\text { Strong........ }\end{array}$ & $\begin{array}{l}\text { 1-2 Deg higher. } \\
\text { Present work. } \\
\text { 1-2 Deg lower. } \\
\text { 10-15 Deg higher. }\end{array}$ \\
\hline
\end{tabular}

a Or until maximum volume is reached at each temperature. This heating rate avoids superheating and minimizes reorganization $[15,16]$, so that the observed melting temperature is that of the largest crystals formed at a given crystallization temperature.

${ }^{\mathrm{b}}$ Or until appreciable recrystallization has occured at each temperature.

When Sample B was held at $38{ }^{\circ} \mathrm{C}, 3$ deg below its initial $T_{m}$, this temperature was too low for complete melting to occur [1] (i.e., for the volume to reach the extrapolated liquidus) over a long time span. As judged by the volume change, the melting was about 45 percent $^{5}$ complete before recrystallization began to predominate. Partial melting and recrystallization are common to semicrystalline polymers below their melting temperatures, but they require a very long time for this rubber. Presumably, if the same specimen had been held at 39 or $40{ }^{\circ} \mathrm{C}$, it would have completely melted ${ }^{6}$ since upon heating to that temperature only a small amount of crystallinity would have remained (see fig. 1 of ref. [1]), and the orientation between crystalline regions would have been partially disrupted. Somewhere between $T_{m}-3 \mathrm{deg}$ and $T_{m}$ lies a point of no return, probably corresponding to the temperature where maximum volume increase occurs during the observation period $\left(50{ }^{\circ} \mathrm{C}\right.$ in figs. 2 and $3)$. Another specimen of stark rubber, from a different source (the "Cramer" sample of refs. [4 and 17]), whose melting point was found in a separate experiment (heating at $1 \mathrm{deg} / 6$ weeks) to be $36.5^{\circ} \mathrm{C}$, reached the liquidus in 23 days at $35^{\circ} \mathrm{C}$, after being heated to $35{ }^{\circ} \mathrm{C}$ at $1 \mathrm{deg} / 5 \mathrm{~min}$. There is some evidence [18]

\footnotetext{
${ }^{5}$ The 60 percent melting referred to in ref. [1] is a numerical error.

${ }^{6}$ This would eliminate the upper "tail" [13] usually observed in the melting curve. See figures 1 and 2 .
}

that a polymer which was quickly heated into the melting range and held there would go on and completely melt, but if slowly heated, it would not.

After Sample B had been kept at $38{ }^{\circ} \mathrm{C}$ for about 10 days, the rate of increase in volume was slow enough so that more than $24 \mathrm{hr}$ was required to be sure that the volume was indeed increasing. After 2 months, the volume appeared to remain constant for 2 to 4 weeks at a time, but a slight increase was actually occurring, as became evident over a longer time. Slow increases in volume near the melting temperature have been observed elsewhere $[11,18,19,20,21]$, although in unoriented systems this does not result in complete melting.

It seems reasonable to interpret the broad melting behavior of Sample A as consisting of two melting ranges overlapped. At the lower temperatures (34 to $41{ }^{\circ} \mathrm{C}$ ) there is a long succession of small volume increases, representing the melting of the less stable room temperature crystals of more recent vintage, whereas the steep rise and upper shoulder result from the melting of the larger, older crystals. In figure 1 it can be seen that the heights of the increases in volume with time become larger at each temperature from 34 to $37{ }^{\circ} \mathrm{C}$, diminish from 37 to $39{ }^{\circ} \mathrm{C}$, then increase again toward $T_{m}$. (This remains true after allowing for differences in time intervals.) In the work described in ref. [4] two distinct melting ranges were observed for a specimen of stark rubber which had undergone additional crystallization. In Sample B, the $38^{\circ} \mathrm{C}$ crystals and the older ones all melt within a narrow $(5 \mathrm{deg})$ range.

The slow rate of recrystallization of stark rubber might be expected at these temperatures, but the apparently slow rate of melting above $34{ }^{\circ} \mathrm{C}$ requires some explanation. Analysis of unpublished data in this laboratory shows stark rubber to have melting rates (equal to $\Delta \overline{V \mid \Delta}$ time at a given temperature) similar to those of rubber crystallized by cooling alone in corresponding parts of the melting curves, but the process of melting takes longer to reach static volume in stark rubber. At $38{ }^{\circ} \mathrm{C}$ this process was observed for a long time, resulting in a relatively large increase in volume. It would seem that this is connected with a slow (because of high viscosity) cooperative relaxation of residual stress in the oriented rubber. The mechanism for this is not clear.

Heating stark rubber several degrees above its $T_{m}$ destroys the orientation so that crystallization by cooling and subsequent melting are the same as in ordinary rubber [1]. Consequently it may be asked whether or not the new crystals formed on storage after the partial melting at $38{ }^{\circ} \mathrm{C}$ are still oriented. Unoriented rubber crystallized by cooling has a negligible rate of recrystallization above $20{ }^{\circ} \mathrm{C}$ and melts near $30{ }^{\circ} \mathrm{C}$ or below. In view of the finite rates of recrystallization at 25 and $38{ }^{\circ} \mathrm{C}$ as well as the high melting temperatures found in the present work, it seems very likely that the new crystals formed on storage of stark rubber are oriented. Direct evidence for this orientation was not obtained. Such orientation would arise from 
a "memory" of previous sites (oriented liquid) or surface nucleation on oriented crystals.

Recrystallization and melting of stark rubber should be possible at still higher temperatures than those observed in this work.

This research was initiated in collaboration with Leo Mandelkern. The author acknowledges many helpful conversations with J. J. Weeks, and appreciates comments and suggestions by P. K. Sullivan, A. J. Bur, and L. A. Wood.

\section{References}

[1] D. E. Roberts and L. Mandelkern, J. Res. NBS 54, 167 (1955) RP2578.

[2] C. J. Newton, L. Mandelkern and D. E. Roberts, J. Res. NBS 55, 143 (1955) RP2613.

[3] C. J. Newton, L. Mandelkern and D. E. Roberts, J. Appl. Phys. 26, 1521 (1955).

[4] L. A. Wood and N. Bekkedahl, J. Appl. Phys. 17, 362 (1946); J. Res. NBS 36, 489 (1946) RP1718; or Rubber Chem. and Technol. 19, 1145 (1946).

[5] D. J. Harmon and H. L. Jacobs, J. Appl. Polymer Sci. 10, 253 (1966).

[6] J. D. Hoffman, J. J. Weeks and W. M. Murphey, J. Res. NBS 63A, 67 (1959).
[7] P. H. Geil, "Polymer Single Crystals," Interscience, New York, p. 361-366, 1963. Some of the curves in figs. V-48 and $\mathrm{V}-52$ yield calculated values of $n$ near 1 (Data of Gubler, Rabesiaka and Kovacs).

[8] R.-J. Roe and W. R. Krigbaum, Polymer 6, 231 (1965).

[9] A. van Rossem and J. Lotichius, Kautschuk 5, 2 (1929); or Rubber Chem. and Technol. 2, 378 (1929).

[10] J. D. Hoffman, SPE Transactions 4, 315 (1964).

[11] J. J. Weeks, J. Res. NBS 67A (Phys. and Chem.) No. 5, 441 (1963).

[12] J. D. Hoffman and J. J. Weeks, J. Chem. Phys. 42, 4301 (1965).

[13] J. D. Hoffman and J. J. Weeks, J. Res. NBS 66A (Phys. and Chem.) No. 1, 13 (1962).

[14] J. D. Hoffman and J. I. Lauritzen, Jr., J. Res. NBS 65A (Phys. and Chem.) No. 4, 297 (1961).

[15] E. Hellmuth and B. Wunderlich, J. Appl. Phys. 36, 3039 (1965); also Tamio Arakawa and B. Wunderlich, J. Polymer Sci. A2, 4, 53 (1966).

[16] B. Wunderlich, Polymer 5, 611 (1964); also D. Bodily and B. Wunderlich, J. Polymer Sci. A2, 4, 25 (1966).

[17] L. A. Wood, N. Bekkedahl and C. G. Peters, J. Res. NBS 23, 571 (1939) RP1253; or Rubber Chem. and Technol. 13, 290 (1940); also L. A. Wood, N. Bekkedahl and R. E. Gibson, J. Res. NBS 35, 375 (1945) RP1677; or J. Chem. Phys. 13, 475 (1945).

[18] P. J. Flory, L. Mandelkern and H. K. Hall, J. Am. Chem. Soc. 73, 2532 (1951).

[19] R. Chiang and P. J. Flory, J. Am. Chem. Soc. 83, 2857 (1960).

[20] D. E. Roberts and L. Mandelkern, J. Am. Chem. Soc. 77, 781 (1955).

[21] R. D. Evans, H. R. Mighton and P. J. Flory, J. Am. Chem. Soc. 72, 2018 (1950).

(Paper 71A3-455) 